\title{
Contribution Of Universities Towards Knowledge Of Millennium Development Goals (MDGS): A Study Of Uganda And Kenya
}

Robert Wamala, Makerere University, Uganda

Jean Chamberlain, Uganda Christian University, Uganda

Mary Sonko Nabachwa, Uganda Christian University, Uganda

\begin{abstract}
This paper examines the contribution of universities towards students' awareness of issues related to Millennium Development Goals (MDGs). The assessment is based on data of 1,920 students randomly selected from universities in Uganda and Kenya. Frequency distributions, the Chisquare test, and complementary log-log regression were used for analysis. About $74 \%(n=$ $1,100)$ of students aware of MDGs $(n=1,484)$ affirmed that they had acquired this information from universities where they were enrolled. In the multivariate assessment, modeled by a range of university and student characteristics, the reported contribution of universities in fostering knowledge of MDGs was more likely among students enrolled in master's programs, those in the sciences, and among males. The findings suggest a high level of awareness of MDGs among university students but a shallow knowledge base of aspects related to the goals. Suggestions for enhancing knowledge of the goals centered on two aspects: i) incorporation of MDGs in curriculum content, particularly in the undergraduate and Arts programs, and ii) widening the dissemination platform of research findings among students.
\end{abstract}

Keywords: Millennium Development Goals, Role of Universities, Uganda and Kenya

\section{INTRODUCTION}

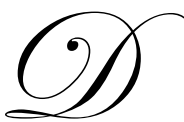

espite the notable progress made over the past decade on each individual Millennium Development Goal (MDG), achieving these goals remains a major challenge, particularly in developing countries. The success attained even in the poorest countries and in the most difficult circumstances demonstrates that the goals can be achieved (UNDP, 2010). That progress is uneven between and within regions and/or countries and often too slow to meet the 2015 deadline (UNDP, 2010) suggests that country-specific interventions are required to help achieve the development goals. This supports literature that suggests differentials by country and by goal for effective policies and interventions with regard to MDGs. However, consensus suggests that most of the goals are unlikely to be achieved by 2015 (CRS, 2010).

Nevertheless, countries must accelerate efforts towards achieving the MDGs within the remaining three years. Among other reasons, achieving the development goals is crucial for the development of the youth (Sergio, 2006). To do so, every individual and/or institution must assume responsibility for achieving the goals rather than pointing to the UN and governments as related literature seems to suggest (for example CRS, 2010). Universities and research institutions have not yet achieved their full potential in aiding in the attainment of these development goals. These institutions of higher learning seem to be inactive participants in the implementation of MDGs since their efforts to integrate MDG-related issues into university learning are few, uncoordinated, and fragmented. A 2011 needs assessment study involving interviews with the academic staff of universities in Botswana and Uganda revealed that there is limited focus on MDGs in the curriculum content (UMI \& University of Botswana, 2011). 
Further, the findings suggest that universities in the two countries are not promoting intellectual engagement on MDGs, resulting in huge capacity gaps and limited community outreach programs and action research on the subject matter (UMI \& University of Botswana, 2011).

Although this may be the case, "...universities are uniquely positioned between the communities and the governments they serve. They are at the core of societies - and often in the rebuilding of broken ones as reflected by the MDGs" (New Straits Times, May 2, 2010). Thus, their role in knowledge building on MDGs cannot be underestimated. This study, therefore, sought to examine the contribution of universities in Uganda and Kenya in building knowledge of MDG-related issues among students enrolled in institutions in the two countries.

\section{DATA AND METHODS}

This study was conducted using a cross-section survey employing a quantitative approach to data and methods. The study population comprised final-year students enrolled in Ugandan and Kenyan universities by January 2011. A multi-stage stratification by countries, university foundation bodies (private vs. public), discipline (science vs. arts) and gender was adopted to obtain a representative sample of students. The sample of 1,920 students was obtained using Cochrane's 1977 sample formulae based on a standard error of $3.2 \%$ and adjusted for a response rate of $83 \%$. Primary data were obtained from students in selected universities and/or academic units using a questionnaire. Data in this work were analyzed at three stages. First, a descriptive summary of students' characteristics (age, gender, program, country, and area of permanent residence) and status of the contribution of universities in fostering knowledge of MDGs were presented using frequency distributions. Second, associations between students and university characteristics by status of contribution towards knowledge of MDGs, the outcome variable, were examined using the Pearson Chi-square test and the probability value. The analysis at this stage helped examine independent associations between independent variables and status of contribution towards knowledge of the goals, the outcome variable. Potential predictors of the outcome variable, for consideration during the multivariate stage, were indentified. Third, the net-impact of student and university characteristics on reported contribution towards knowledge of MDGs was established using a binomial model with a complementary $\log -\log$ function (Hilbe, 1996). Associations with the outcome variable were established at the 5\% level, unless stated otherwise.

\section{RESULTS OF THE STUDY}

The students examined in this study are characterized as follows: predominantly undergraduate students (83.8\%), and enrolled in private universities (72.5\%); slightly more than half (51\%) were from Kenyan universities and about four in every nine (44\%) were females.

\section{Contribution of Universities towards Knowledge of MDGs}

Of the 1,920 students, $1,484(77.3 \%)$ were aware of the MDGs. The results suggest a high level of awareness about MDGs among students enrolled in Ugandan and Kenyan universities. In light of other sources of knowledge on MDGs, the students were asked whether their universities had contributed towards their knowledge of the development goals. Table 1 presents a distribution summary of the students' responses regarding the contribution of universities towards their knowledge of MDG-related issues.

Table 1: Students' Responses to whether Universities Contributed Towards Knowledge of MDGs

\begin{tabular}{lcc}
\hline Response & Frequency & Percentage \\
\hline Yes & 1,100 & 74.1 \\
No & 384 & 25.9 \\
\hline Total & $\mathbf{1 , 4 8 4}$ & $\mathbf{1 0 0}$ \\
\hline Note: The analysis is based on students who were aware of $M D G s(n=1,484)$
\end{tabular}

According to Table $1,74.1 \%$ of the students answered in the affirmative when asked if academic institutions had contributed to their knowledge of MDG-related issues. The results suggest that universities in Uganda and Kenya are active participants in fostering knowledge of the development goals among their students. 


\section{Differential in Contribution of Universities towards Knowledge of MDGs}

The association of student and university characteristics by status of contribution towards knowledge of MDGs was examined using the Chi-square test and the probability value; associations were established at 5\% level. The relationships between the variables are presented using cross-tabular analysis in Table 2 .

Table 2: Differentials in Reported Contribution of Universities towards Knowledge of MDGs

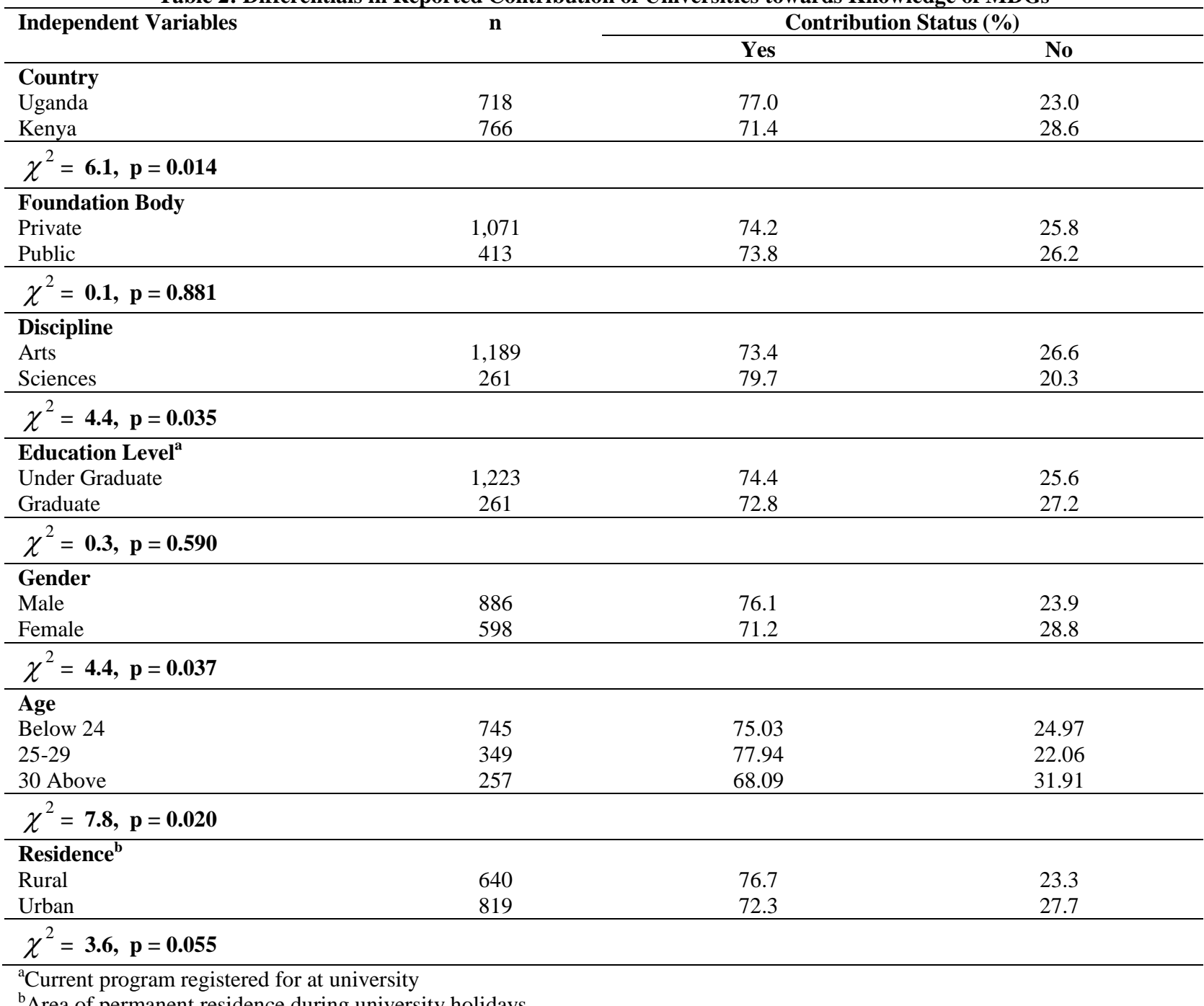

${ }^{\mathrm{b}}$ Area of permanent residence during university holidays

Significant associations with the reported contribution of universities towards students' knowledge of MDGs were established by student characteristics - country of residence, discipline of study, gender, and age ( $\mathrm{p}<$ 0.05). As shown in Table 2, students in Uganda (77.0\%) — those in science disciplines (79.7\%), males (76.1\%), and those in lower age groups (below 29)_reported a higher proportion of contribution from institutions in their knowledge of MDGs. To establish the net influence of these variables, a complementary log-log regression was adopted at the multivariate level. Although the remaining variables did not yield a significant association $(\mathrm{p}>0.05)$ with the outcome variable (reported contribution of universities towards knowledge of MDGs), they were included in the analysis at the multivariate stage. The variables were considered very important characteristics of students; thus, they were controlled for in the third stage of the analysis. 
To this end, Table 3 presents regression estimates for the likelihood of affirming the contribution of universities towards students' knowledge of MDG-related issues. The table comprises beta coefficients $(\beta)$, exponentiated coefficients ( $\operatorname{Exp}(\beta)$ ), the standard error of coefficients (Std. Err), and probability values (p-value). The findings are summarized in the subsequent sections.

Table 3: Likelihood Estimates of Reported Contribution of Universities towards Students' Knowledge of MDGs

\begin{tabular}{|c|c|c|c|c|}
\hline Independent Variables ${ }^{\mathrm{a}}$ & $\beta$ & $\operatorname{Exp}(\beta)(95 \% \mathbf{C I})^{\mathbf{b}}$ & Std. Err & p-value \\
\hline $\begin{array}{l}\text { Country } \\
\text { Uganda } \\
\text { Kenya } \\
\end{array}$ & -0.055 & $\begin{array}{c}\mathbf{1} \\
0.94(0.82-1.07) \\
\end{array}$ & 0.067 & $0 . \dot{4} 09$ \\
\hline $\begin{array}{l}\text { Foundation Body } \\
\text { Private } \\
\text { Public } \\
\end{array}$ & 0.033 & $\begin{array}{c}\mathbf{1} \\
1.03(0.89-1.19) \\
\end{array}$ & 0.073 & $0 . \dot{6} 47$ \\
\hline $\begin{array}{l}\text { Discipline } \\
\text { Sciences } \\
\text { Arts } \\
\end{array}$ & $-0 . \dot{2} 66$ & $\frac{\mathbf{1}}{0.76(0.65-0.90)}$ & 0.083 & 0.001 \\
\hline $\begin{array}{l}\text { Program } \\
\text { Under-graduate } \\
\text { Graduate }\end{array}$ & $0 . \dot{220}$ & $\frac{\mathbf{1}}{1.24(1.02-1.51)}$ & $0 . \dot{100}$ & $0 . \dot{028}$ \\
\hline $\begin{array}{l}\text { Gender } \\
\text { Male } \\
\text { Female }\end{array}$ & $-0 . \dot{2} 15$ & $\begin{array}{c}\mathbf{1} \\
0.80(0.70-0.91) \\
\end{array}$ & $0 . \dot{065}$ & $0 . \dot{001}$ \\
\hline $\begin{array}{l}\text { Age } \\
\text { Below 24 } \\
25-29 \\
30 \text { and Above }\end{array}$ & $\begin{array}{c}0.032 \\
-0.175\end{array}$ & $\begin{array}{c}\mathbf{1} \\
1.03(0.88-1.20) \\
0.83(0.68-1.02)\end{array}$ & $\begin{array}{c}\dot{0} \\
0.102\end{array}$ & $\begin{array}{l}0.678 \\
0.087\end{array}$ \\
\hline $\begin{array}{l}\text { Permanent Residence } \\
\text { Urban } \\
\text { Rural }\end{array}$ & 0.009 & $\begin{array}{c}\mathbf{1} \\
1.01(0.88-1.14)\end{array}$ & $0 . \dot{064}$ & $0 . \dot{885}$ \\
\hline
\end{tabular}

Note: Likelihood Ratio Chi-square (8) = 29.2, $p<0.01, n=1680$

${ }^{\mathrm{a} B}$ Bold variable items represent reference categories adopted

${ }^{\mathrm{b}}$ Exponentiated coefficients (Relative Risk) and their 95\% Confidence Intervals

\section{Regression Diagnostics}

Specification errors of the link function adopted in the final model were examined using the link test. Three aspects were examined: i) Is the Complementary log-log transformation the correct functional form of the outcome variable? ii) Is a linear combination of student and university characteristics (independent variables) supported? iii) Is the complementary log-log function a linear combination of the independent variables?

Table 4: Specification Errors of Link Function

\begin{tabular}{lccc}
\hline Complementary Log-log Function & Coef. & Std. Err & p-value \\
\hline -hat $^{\mathrm{a}}$ & 0.894 & 0.217 & 0.000 \\
_hatsq $^{\text {b }}$ & 0.668 & 0.759 & 0.379 \\
Cons. & -0.017 & 0.038 & 0.648 \\
\hline
\end{tabular}

Note: Specification Error test of model in Table 3

${ }^{\mathrm{a}}$ Hat Statistic, ${ }^{\mathrm{b}}$ Hat-square Statistic

The results of the specification error test in Table 4 show that the complementary log-log function was well specified, as predicted by the Hat statistic $(\mathrm{p}<0.05)$. The Hat-square statistic shows that no additional variables were significant ( $\mathrm{p}>0.05)$. Thus, a linear combination of predictors (student and university characteristics) on the complementary log-log transformation function of the outcome variable is an appropriate specification for data adopted in the investigations. 


\section{Summary of the Findings}

According to Table 3, significant associations with reported contribution of universities towards students' knowledge of MDG-related issues were observed for the gender, discipline of study, and graduate versus undergraduate type of registration variables $(\mathrm{p}<0.05)$. These results are summarized as follows:

1. Students in the arts discipline were less likely to report contribution from their universities towards knowledge of MDG-related issues (Relative Risk $=0.76$ ).

2. Female students were less likely to report contribution from their universities towards knowledge of MDGrelated issues (Relative Risk $=0.80$ ).

3. Students enrolled in master's programs were more likely to report contribution from their universities towards knowledge of MDGs (Relative Risk $=1.24$ ).

Non-significant association with the likelihood of a reported contribution by universities towards knowledge of MDG issues was observed for the student characteristics of country of residence, private-public variation in university foundation bodies, rural-urban residence, and age of the student ( $p>0.05)$. In other words, students' reporting of university contribution towards knowledge of MDG issues did not vary significantly with these variables.

\section{DISCUSSION AND CONCLUSIONS}

A high proportion of students (77.3\%) were aware of MDGs. The figure represents students who reported having any knowledge of issues related to the development goals. The findings are contrary to the Cairo University MDG awareness study that reported that three-quarters (75\%) of students were unaware of the development goals (Cairo University \& UNDP, 2010). However, further analysis of students aware of MDGs in this study revealed that only $44.4 \%$ were able to mention the right number (8), while only $47.7 \%$ knew the correct deadline (2015) for the achievement of the goals. The proportion that was aware of both the right number and the target date for the achievement of the goals was $23.4 \%$. This low figure suggests a shallow knowledge base of issues related to the goals despite the high level of awareness of MDGs. It also supports literature that suggested a dearth of concrete MDG-focused programs among Ugandan universities (MFPED, 2010; UMI \& University of Botswana, 2011). The findings suggest that universities in Uganda and Kenya are not playing an optimal role in enhancing the knowledge of these development goals among their students. This work presents a sub-optimal contribution of universities in Uganda and Kenya towards knowledge of issues related to MDGs among under-graduates, students enrolled in the arts/humanities, and among females. In light of the fact that more males than females enroll for science courses (for example, NCHE, 2007; UNCST, 2010), this work indentifies a sub-optimal contribution of universities in fostering knowledge of these goals in mainly two sub-groups - undergraduates and students in arts-related disciplines.

In a 2011 study of the enhancement of East African universities' contribution towards the attainment of MDG-5, inability of universities in Uganda and Kenya to contribute effectively towards knowledge building on MDG-related issues was attributed to shortfalls in four major aspects: i) availability of collaborative arrangements or social networks with external civil societies and/or NGOs; ii) platforms to disseminate research findings to students, faculty, and community (for example, seminars and workshops); iii) provisions for revision of curriculum content to accommodate aspects related to MDGs; and iv) consultations with relevant stakeholders outside the university procedures with relevant stakeholders outside the universities during the review of curriculum content. In particular, the UCU 2011 status report presents the following statistics on the abovementioned aspects: about $23 \%(\mathrm{n}=442)$ of students reported attending seminars or workshops organized by their units or universities addressing MDG-related issues; $38 \%$ of faculty representatives attested to collaborative arrangements with external civil societies, while slightly more than half $(52.2 \%)$ claimed to have reviewed their curriculum content in the four years preceding the study. Moreover, there was barely any consultation with relevant stakeholders outside the university to review the curriculum. The UCU 2010 evaluation also investigated institutions responsible for fulfilling MDGs. The findings suggested that students and faculty representatives felt that governments, NGOs, and the UN were the main bodies responsible for fulfilling the goals rather than the university (UCU, 2011). The results corroborate recent literature that presents the UN and governments as the institutions responsible for fulfilling MDGs (CRS, 2010). The fact that both students and faculty felt that they did not have a critical role in the attainment of the development goals underscores the need for mapping out a clear path in ensuring that such an understanding is attained. 
On the other hand, the 2010 conference of the Association of Commonwealth Universities (ACU) attributes the inability of universities to effectively contribute to knowledge building on MDGs to the failure of governments and international donors to recognize higher education in current MDGs. In any case, the findings in this work demonstrate a sub-optimal contribution from Ugandan and Kenyan universities towards fostering knowledge of MDGs with regard to teaching, research, and dissemination of findings on MDG-related issues. These three main areas of contribution need to be strengthened to enhance awareness as well as create a good knowledge base of issues related to MDGs among students. Despite the fact that this study focused on students enrolled in Ugandan and Kenyan universities, the situation in other African institutions may not be very different. It is highly probable that students registered in other African universities have a similar level of knowledge of MDGs.

\section{AUTHOR INFORMATION}

Robert Wamala, Ph.D. Student, Institute of Statistics and Applied Economics, Makerere University, Uganda. E-mail: rwamala@isae.mak.ac.ug. Corresponding author.

Dr. Jean Chamberlain, Uganda Christian University, Save the Mothers, Uganda. E-mail: jchamber@ucu.ac.ug

Dr. Mary Sonko Nabachwa, Uganda Christian University, Department of Development Studies, Uganda. E-mail: maryssonko@yahoo.co.uk

\section{REFERENCES}

1. Association of Commonwealth Universities (April, 2010). Contribution of Universities to the Sustainable Achievement of the Millennium Development Goals. Proceedings of the ACU Conference of Executive Heads, South Africa.

2. Cairo University \& UNDP (2010). MDGs Awareness Initiative in Cairo University. Research Document. Community and Environment Service Sector, Cairo University. Retrieved from www.mdgs.cu.edu.eg/MDGs\%20Awareness.pdf

3. CRS (December, 2010). The Millennium Development Goals: The September 2010 UN High-level Meeting. Status Report for Congress, Congregational Research Service.

4. Sergio, B. (2006). Achieving the Millennium Development Goals Is a Crucial Element in the Development of the Youth. MDG Global Watch Journal, 1(2).

5. Hilbe, J.M. (1996). Maximum-likelihood Complementary Log-log Regression. Stata Technical Bulletin 32: $19-20$.

6. MFPED (2010). Millennium Development Goals Report for Uganda 2010: Accelerating Progress improving maternal health. Ministry of Finance Planning and Economic Development.

7. NCHE (2007). The State of Higher Education and Training in Uganda. A Summary Report on Higher Education Delivery and Institutions. National Council for Higher Education.

8. UCU (2011). The Enhancement of East African Universities' Contribution towards the Attainment of Millennium Development Goal -5. Baseline report, Uganda Christian University.

9. UMI \& University of Botswana (2011). Popularizing Millennium Development Goals in University Education. Policy Brief, Retrieved from www.umi.ac.ug/manage/newsletter/1328198608.pdf

10. UNCST (2010). Science, Technology and Innovation. Uganda's Status Report 2008/2009. Uganda National Council for Science and Technology.

11. UDNDP (2010). The Path to Achieving the Millennium Development Goals: A Synthesis of Evidence from around the World. Status Report, United Nations Development Programme.

12. Central Statistics Office (2010). Botswana Millennium Development Goals Status Report 2010. 